
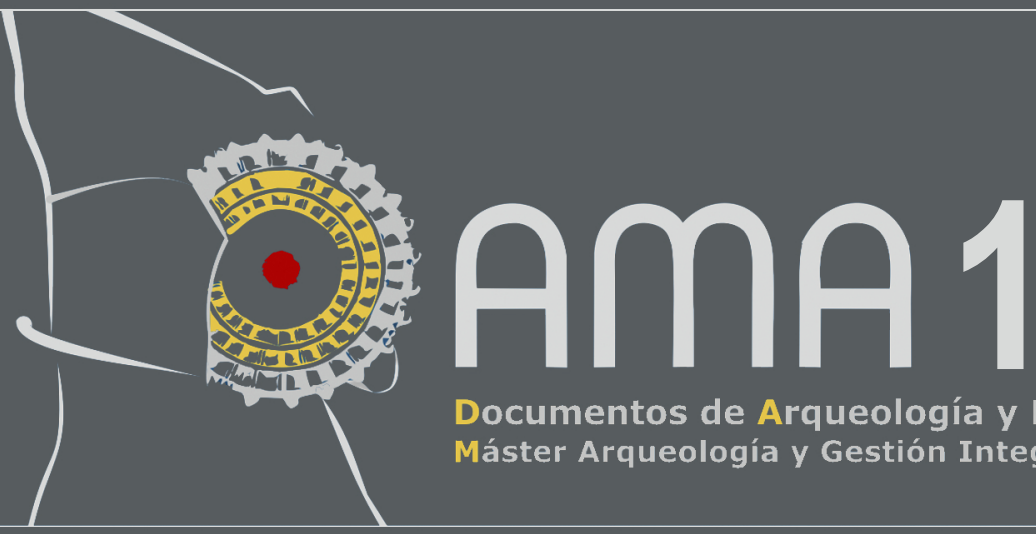

Documentos de Arqueología y Patrimonio Histórico

Máster Arqueología y Gestión Integral del Patrimonio de la Universidad de Alicante

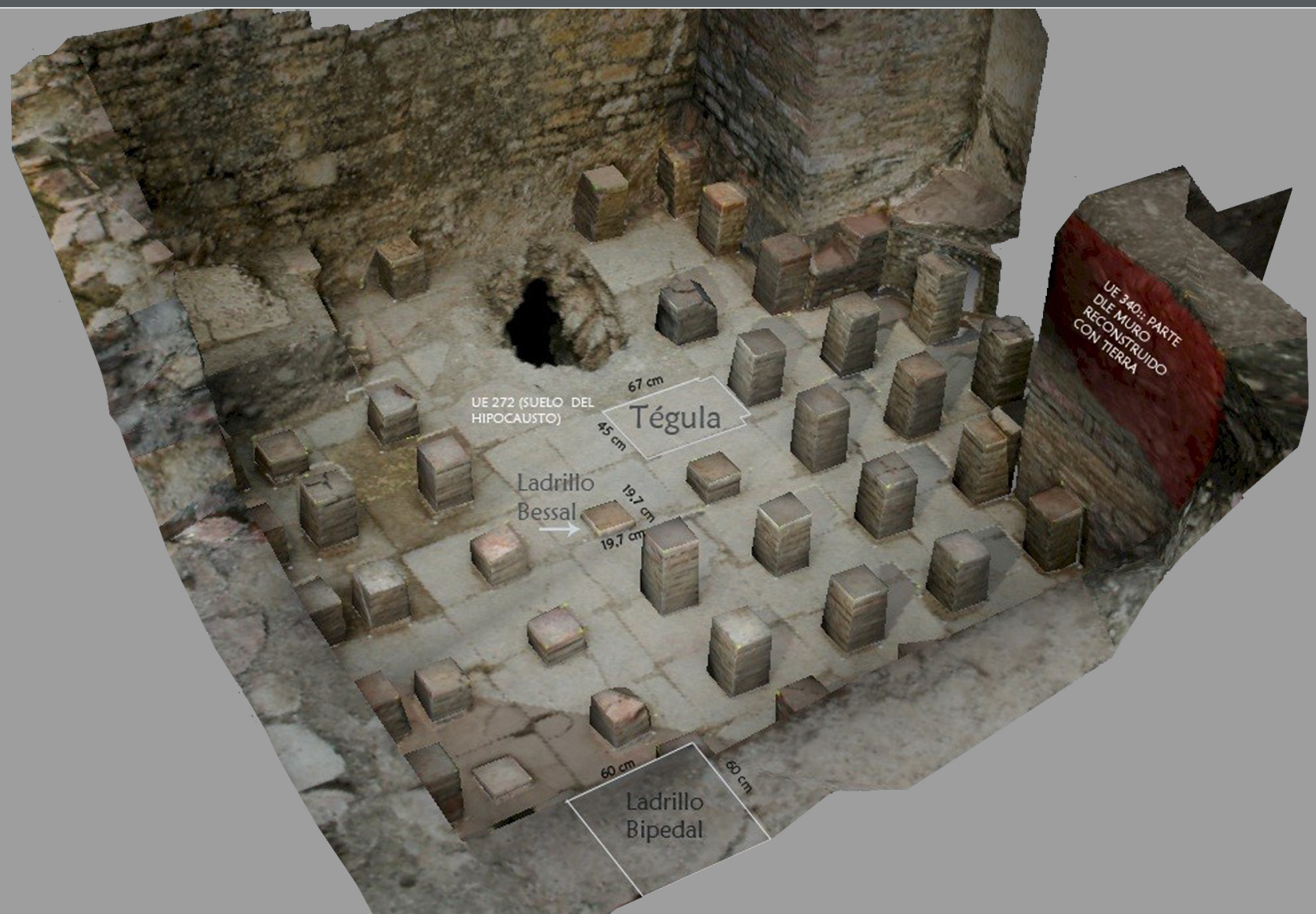

Documentos de Arqueología y Patrimonio Histórico Revista del Máster Universitario en Arqueología Profesional y Gestión integral del Patrimonio 



\section{DAMA 1}

\section{6}

DOCUMENTOS DE ARQUEOLOGÍA Y PATRIMONIO HISTÓRICO DEL MÁSTER UNIVERSITARIO EN ARQUEOLOGÍA PROFESIONAL Y GESTIÓN INTEGRAL DEL PATRIMONIO DE LA UNIVERSIDAD DE ALICANTE 


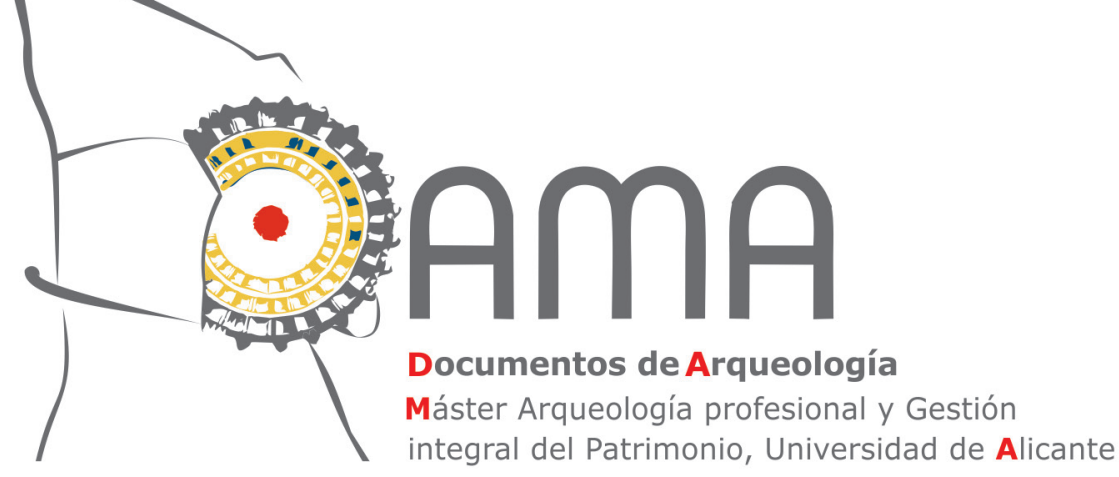

La revista electrónica DAMA. Documentos de Arqueología y Patrimonio Histórico surge como servicio para todos aquellos alumnos del Máster en Arqueología Profesional y Gestión Integral del Patrimonio de la Universidad de Alicante que se están iniciando en la investigación y cuya primera aportación a nuestra disciplina suele ser su Trabajo de Fin de Máster (TFM). Estos proyectos en muchos casos representan casi todo un curso de trabajo y esfuerzo, y con frecuencia quedan inéditos.

El objetivo de esta revista es ofrecer un medio que facilite la publicación de los resultados de sus TFM. La edición se presenta en versión digital y cuenta con su correspondiente ISSN. Se publica de forma anual en el sitio web de la Universidad de Alicante (http://web.ua.es/es/dama/) y en su repositorio (RUA). Los artículos publicados son descargables en formato PDF.

\section{Consejo de Redacción}

Directores (Coordinadores del Máster)

Carolina Doménech Belda

Fernando Prados Martínez

\section{Secretaria de Edición}

Julia Sarabia Bautista

\section{Vocales}

Los miembros de la Comisión Académica del Máster Universitario en Arqueología Profesional y Gestión del Patrimonio (http://dprha.ua.es/es/magip/comision-academica.html)

\section{Edita}

Máster Universitario en Arqueología Profesional y Gestión Integral del Patrimonio Departamento de Prehistoria, Arqueología, Historia Antigua, Filología Griega y Filología Latina

Facultad de Filosofía y Letras II

Universidad de Alicante

Ctra San Vicente del Raspeig s/n

E-03690 San Vicente del Raspeig (Alicante)

Web:http://dprha.ua.es

Teléfono: (+34) 965903663

Fax: (+34) 965903823

E-mail: revista.dama@ua.es

\section{ISSN}

$2530-2345$

\section{Portada}

Modelo fotogramétrico de un hypocaustum romano realizado por Ana Charquero 
EDITORIAL

Coordinación del máster

ENTREVISTA A SOLVEIG NORDSTRÖM: UNA MIRADA HACIA EL PASADO DE LA ESCUERA

Raúl Berenguer González ..

\section{ARQUEOLOGÍA Y MÉTODO}

EL ESTUDIO DE LOS MATERIALES CONSTRUCTIVOS DE TIERRA DEL CABEZO DEL POLOVAR (VILLENA, ALICANTE): APORTACIÓN A LAS FORMAS CONSTRUCTIVAS DE DOS PEQUEÑAS EDIFICACIONES CAMPESINAS DE LA EDAD DEL BRONCE EN EL LEVANTE PENINSULAR

María Pastor Quiles

VIVIENDAS POSTALAYÓTICAS: UNA APROXIMACIÓN A LOS ESPACIOS DOMÉSTICOS EN EL ARCHIPIÉLAGO BALEAR (550-123 ANE)

Octavio Torres Gomáriz

LAS FLOTAS DE GUARNICIÓN ROMANA EN LAS COSTAS DE HISPANIA A PARTIR DE LAS FUENTES EPIGRÁFICAS

Sergio Lledó Ramírez

UNA APROXIMACIÓN A LA RECONSTRUCCIÓN DEL PAISAJE HISTÓRICO: EL PROYECTO L'ALMISSERÀ Diana López Arroyo

NUEVAS PERSPECTIVAS PARA EL ESTUDIO ARQUEOLÓGICO DEL POBLAMIENTO RURAL MEDIEVAL EN ASPE (ALICANTE): HUERTAS Y ALQUERÍAS JUNTO AL RÍO TARAFA

Felipe Mejías López

ARQUEOLOGÍA DE LAS GUERRAS CARLISTAS

Iván Roldán Vergarachea

LA CERÁMICA DE USO ARQUITECTÓNICO EN NOVELDA: LA AZULEJERÍA DE FINALES DEL SIGLO XIX Y PRINCIPIOS DEL XX

Natalia Sala Pérez

PRÁCTICA Y USOS DE LA FOTOGRAMETRÍA DIGITAL EN ARQUEOLOGÍA

Ana $M^{a}$ Charquero Ballester.

\section{GESTIÓN Y PUESTA EN VALOR DEL PATRIMONIO}

ARQUEÓLOGOS CON DISCAPACIDAD. ARQUEOLOGÍA INCLUSIVA

Ana Samaniego Espinosa

"LES COVES DELS PESCADORS DE EL CAMPELLO": PROPUESTA DE RECUPERACIÓN, PUESTA EN VALOR Y USO PÚBLICO DE UN PATRIMONIO OLVIDADO

Ana Isabel Castro Carbonell .

LA COLONIA DE SANTA EULALIA. ESTUDIO Y PROPUESTA DE RECUPERACIÓN

Héctor de Arriba González

PROYECTO DE PUESTA EN VALOR DE LOS RESTOS DE LA GUERRA CIVIL EN LA CIUDAD DE ALICANTE

Leticia Victoria González Chouciño

ANTEPROYECTO MUSEOGRÁFICO DEL MUSEO DE HISTORIA DE SAX

Alberto Ochoa García

EL CONGRESO DE MÁSTER: UNA PROPUESTA DIDÁCTICA DEL MÁSTER DE ARQUEOLOGÍA DE LA UNIVERSIDAD DE ALICANTE

Ignasi Grau Mira, Sonia Gutiérrez Lloret, Carolina Doménech Belda, Julia Sarabia Bautista 



\title{
ENTREVISTA A SOLVEIG NORDSTRÖM: UNA MIRADA HACIA EL PASADO DE LA ESCUERA
}

\author{
Raúl Berenguer González
}

Yo caí allí como un copo de nieve del norte ¡Pum! Así, y comencé a excavar...

Solveig Nordström

\section{RESUMEN}

Este artículo pretende ser un pequeño epílogo al Trabajo Fin de Máster presentado en septiembre de 2012, "Análisis microespacial del templo ibérico de La Escuera (San Fulgencio, Alicante), dirigida por la profesora Dra. Feliciana Sala. Presentamos aquí una entrevista a la Dra. Solveig Nordström, autora de la primera campaña de excavación en el poblado ibérico de La Escuera a comienzos de la década de los años 60, con el fin de ampliar el capítulo de historiografía del yacimiento en cuestión y dar a conocer otras aportaciones de esta arqueóloga a la arqueología alicantina más allá del importante y mediático episodio del rescate del Tossal de Manises.

Palabras clave: Solveig Nordström, La Escuera, templo ibérico, entrevista, historiografía.

\begin{abstract}
This paper has the purpose of being a support for the Master's dissertation "Análisis microespacial del templo ibérico de La Escuera (San Fulgencio, Alicante). Presented in September 2012 and supervised by the professor Feliciana Sala. In here, an interview to the Doctor Solveig Nordström is presented, as she supervised the first archaeological campaing in the Iberian settlement "La Escuera", at the beginning of the 60s. The purpose is to extent this chapter of this historiography of the site and to show more of her archaeological research in Alicante, beyond the rescue of the "Tossal de Manises".
\end{abstract}

Key words: Solveig Nordström, La Escuera, Iberian temple, interview, historiography. 


\section{INTRODUCCIÓN}

De sobra es conocida la figura de Solveig Nordström en el marco de la arqueología alicantina, principalmente por el hecho acontecido allá por los años 60, cuando esta joven arqueóloga de origen sueco se plantó delante del imponente bulldozer y evitó así que el yacimiento arqueológico del Tossal de Manises fuese víctima de la creciente especulación inmobiliaria que tan fuerte pisaba por esas décadas. Poco tiempo después, como todos sabemos, la ciudad de Lucentum fue declarada Monumento Histórico Artístico Nacional, y poco a poco, con el intenso trabajo de muchos arqueólogos y los esfuerzos por parte de la Diputación de Alicante y el MARQ, hoy en día podemos disfrutar del único parque arqueológico de la Comunidad Valenciana.

En muchas ocasiones sólo se menciona a Solveig Nordström por este mediático acontecimiento, quedando eclipsado un sinfín de trabajos y publicaciones ${ }^{1}$ e iniciando uno de los estudios sobre cerámicas ibéricas más pioneros del momento, no superados hasta el momento (Rosser, 2015, p. 270) y que sin duda han aportado una gran cantidad de conocimiento a la historia antigua y a la arqueología alicantina. A decir verdad fue ella quien, empleando la arqueología como fuente histórica, dio más impulso a la tesis de José Lafuente Vidal sobre la presencia cartaginesa en las costas alicantinas, hecho muy novedoso para los estudios de la época (Sala, 2010, p. 938). Poco después saldría a la luz una de sus obras más conocidas, Los cartagineses en la costa alicantina.

Por estas y otras razones hemos creído conveniente indagar en un episodio de la trayectoria investigadora de la Dr. Solveig Nordström, más allá de los hechos que acontecieron en el Tossal de Manises. Nos propusimos elaborar una entrevista a nuestra protagonista con el fin de recabar datos acerca de uno de sus primeros trabajos arqueológicos en Alicante: la campaña arqueológica en el yacimiento ibérico de La Escuera, situado en el municipio alicantino de San Fulgencio,

Quisimos hacer de ésta una entrevista distendida y amena, agradable tanto para la entrevistada como para el entrevistador, y esperemos que también para el lector que ahora lee estas líneas. Quedan en un segundo plano los datos científicos que, debido a lo lejano en el tiempo que quedan estas experiencias, resulta harto complicado de recuperar para el presente por parte de su protagonista, pero que quedaron plasmados de manera magistral en su memoria de excavación (Nordström, 1967). Se trata pues, de una entrevista donde ella nos transmite sus vivencias, sentimientos e impresiones durante las excavaciones en La Escuera, los hechos curiosos allí acontecidos, el trato con el personal de la finca, algunos problemas durante la campaña de excavación, la relación que mantuvo con otros personajes de la arqueología alicantina de este período, o recuerdos entrañables de cómo se produjeron algunos de los hallazgos.

Otro de los objetivos de este trabajo se centra en el hecho de crear un documento introductorio a la historiografía del yacimiento de La Escuera, que sin duda es necesario realizar. Con ello se intenta aportar valor a este campo de la historia. Entendemos que es un apartado muy importante para el estudio y la investigación de cualquier sitio arqueológico. Aunque a simple vista no lo parezca, indagar en el pasado investigador puede abrirnos muchas puertas de cara a la investigación futura. Conocer cómo comenzaron los trabajo arqueológicos, porqué éstos fueron motivados, quién los llevó a cabo, qué actuaciones se ejecutaron, qué corrientes historiográficas predominaban en ese momento, así como la interpretación que se hacía de los resultados obtenidos, nos puede mostrar las vías de cómo hemos llegado a conocer ciertos aspectos y conclusiones que hoy tenemos de nuestros yacimientos y mirar hacia el futuro investigador partiendo de unas bases que otros investigadores nos han ido proporcionando a lo largo del tiempo.

1 Adjuntamos en el apartado de bibliografía una relación de las mismas. 
Por otro lado queremos aprovechar la oportunidad de tener entre nosotros a una parte de nuestra "historia viva" y recabar información de primera mano y, en primera persona, sobre unos acontecimientos que tuvieron lugar hace ya más de medio siglo, lo que hace de este encuentro algo más singular todavía si cabe. Este encuentro con la historia lo hemos querido transformar a su vez en un documento escrito, sonoro y visual ${ }^{2}$ que si resultase válido, podría pasar a formar parte de la historia oral alicantina como patrimonio inmaterial.

\section{BREVE BIOGRAFÍA DE SOLVEIG NORDSTRÖM}

Solveig Nordström nació en Estocolmo el día 12 de julio de 1923 en su propio domicilio, sito por entonces en Hagagatan (Calle de Haga) número 44, en el seno de una familia modesta pero en un hogar muy feliz, pobre de cosas materiales pero rica y abundante en cultura. Es hija única. Su padre, Fritjof Nordström, (Fritz como lo conocían sus más allegados), trabajó como regente de imprenta del diario "Dagens Nyheter" (Noticias del día). Su madre, Anna Nordström, sacrificó sus estudios de magisterio para dedicarse por completo a la educación de Solveig.

Más tarde ingresó en la Universidad de Estocolmo para estudiar, en un primer momento, la titulación de literatura, y posteriormente tendría lugar su formación en arqueología, donde tuvo la oportunidad de profundizar en el conocimiento de latín y griego. Su gran mentor en esta etapa como estudiante fue el doctor en arqueología Gösta Säflund, por el que Solveig siempre ha mostrado un entrañable cariño y admiración.

Tras finalizar sus estudios en arqueología, decidió poner rumbo a España, donde ejercería su profesión como arqueóloga, centrándose en la investigación de la cerámica ibérica procedentes de yacimientos como el Tossal de Manises, La Escuera, El Monastil, El Puig d'Alcoy, El Tossal de la Cala o Coimbra del Barranco Ancho, entre otros, así como su colaboración y trabajo en el museo arqueológico provincial de Alicante.

Finalmente leyó su tesis doctoral en la Universidad de Estocolmo el día 3 de junio de 1969 (Nordström, 1969 - 1973).

\section{LA ENTREVISTA.}

Comienza Solveig relatando como llegó a España en el año 1955. En aquél momento ella estaba trabajando en la Acrópolis de Atenas, seguramente realizando alguna investigación a través del Instituto Sueco en Roma ${ }^{3}$, el cual siempre dirigió sus miradas al estudio de la historia y la arqueología clásica en Grecia e Italia. Pero lo que realmente le interesaba a esta inquieta joven por aquél entonces era el estudio del pasado de la Península Ibérica. El motivo siempre lo tuvo muy claro:

- La historia antigua queda incompleta sin España. Yo me encontraba obligada a ir a España, trabajar en España.

Con tal pretexto propuso a profesores y alumnos viajar a España. Sin embargo debemos ponernos en su contexto histórico. Suecia era un país liberal, con una monarquía estabilizada, una economía próspera y una cultura rica. España estaba inmersa en plena dictadura franquista, donde existían unas rígidas costumbres conservadoras, muy distintas a su país de origen; la libertad de expresión estaba muy acotada y el país vivía inmerso en un estado de pobreza severa y encerrada en sus propias fronteras; el cambio de aires pues, no se antojaba nada fácil, pero su pasión por el estudio de la arqueología ibérica no supuso una barrera para una valiente Solveig, que ante la negativa de

2 La entrevista fue transcrita y grabada en audio y vídeo.

3 Istituto Svedese di Studi Classici a Roma (Svenska Institutet I Rom). 
profesores y alumnos por el miedo generado, decidió hacer las maletas rumbo a su destino. Nos relata brevemente su experiencia en este viaje. De entrada afirma que fue algo complicado, pues ella nunca había visto un avión. La travesía comenzó en barco, donde suponemos que partió desde la costa sur de Suecia hasta Dinamarca, y una vez allí fue enlazando trenes hasta llegar a España. Cabe resaltar que el último tramo del viaje lo hizo a lomos de un burro.

Una vez en España, se dedicó a recorrer los museos de cada ciudad que visitaba.

- Yo he de agradecer mucho a los directores de los museos de España porque me dejaron entrar y vivir en los museos. Yo pasaba la noche en los museos, sí, haciendo lo que yo quería. Y claro yo aprovechaba para trabajar, dibujando y tomando medidas. Y hasta en Alcoy me acuerdo que me llevaba un saco al hotel para trabajar por la noche.

Las primeras noticias que tenemos de Solveig en Alicante las recoge el diario Información en su publicación del día 30 de diciembre de 1955 (página 8), en la cual se la describe como una licenciada sueca "rubia de figura esbelta, con gafas estilo Marilyn y que habla correctamente el castellano" que se dispone a comenzar prácticas arqueológicas en Alicante.

Para ello preguntó por algún arqueólogo que le pudiese introducir en el estudio de la arqueología española. Le recomendaron hablar con don José Lafuente Vidal, que se centraba en la reorganización y catalogación de piezas en el museo arqueológico provincial de Alicante en ese momento (Roca, 2006, p. 161). Cargada con sus maletas, más llenas de ilusión que de cosas materiales, tomó rumbo hacia la céntrica calle alicantina César Elgueazabal 7, donde vivía por aquél entonces Lafuente. Allí fue recibida con los brazos abiertos y entablaron una relación maestro-alumna que con el tiempo les unió prácticamente como a una familia. A partir de este momento Solveig Nordström quedaría anclada en Alicante para el resto de su vida.

- El museo estaba en un desorden que no se puede describir. Todo revuelto. Era el sacerdote don José Belda, muy reverendo ¿verdad? Pero no era arqueólogo, no, y claro el museo estaba así y llamaron a Lafuente para ponerlo un poco en orden, pero era muy difícil (apunta con una sonrisa). Pero él me preguntó a mí si yo quería ayudarle y me hizo muy feliz. Estuvimos allí intentando colocar cosas los dos juntos.

José Lafuente, que a partir de entonces se convertiría en su principal mentor y valedor, le pondría al tanto del estado de la cuestión acerca de la arqueología alicantina, en especial sobre los problemas que en ese momento se estaban produciendo en los terrenos de Lucentum (entre otras cosas) y comenzó a colaborar de manera muy activa, día y noche, en el museo arqueológico. Así la describía el periodista José Vidal Masanet en una entrevista publicada el 23 de abril de 1960 (página 3) del periódico Información de Alicante:

"Trabaja de forma incansable. En las excavaciones agarra la piqueta y no le rinden las horas. Resulta increíble. El entusiasmo la mantiene y su método de vida. No bebe ni fuma alimentándose única y exclusivamente de fruta y verduras, leche y alguna variedad de quesos."

\subsection{Los antecedentes de la excavación.}

En un día incierto de aquél año 1959, según Solveig, llegó al museo un chico joven. Portaba varios fragmentos de cerámica, se presentó y comentó que venía desde la finca de La Escuera, cerca de Guardamar del Segura, desvelando que durante la roturación de tierras aparecían multitud de tiestos 
en superficie. Ante tal noticia Solveig propuso a Lafuente acudir a visitar el lugar de los hallazgos y fue este mismo empleado quien les propuso ir en su coche. Una vez allí fue el propio administrador de la finca de La Escuera, Vicente García Calabuig, quien les invitó a ambos a observar los hallazgos: una gran cantidad de restos cerámicos, algunos de ellos pintados y el saculum de monedas cartaginesas conocido como el tesorillo de La Escuera ${ }^{4}$.

- Me acuerdo también de un saquito, una bolsita de tela de monedas, sí, pero estaban las monedas tan pegadas una a la otra que era como... como una bola, una bola metálica, pero no hemos podido separarlas, pero era evidente que habían colocado un montón de monedas juntas en una bolsa de tela y lo habían escondido en la tierra, sí.

Desde ese momento Solveig Nordström quiso excavar allí por todos los medios, a pesar de la prácticamente nula actividad de la Comisión Provincial de Monumentos de Alicante en estos momentos (Rosser, 2015, 305), organismo que se encargaba de la investigación, conservación y difusión del patrimonio arqueológico durante la época del franquismo, incluidas las intervenciones arqueológicas. José Lafuente trató de explicar a Solveig que en España no es tan fácil excavar, que previamente había que pedir un permiso a la Universidad de Valencia y formar una comisión. Poco tiempo después se compuso dicha comisión integrada por José Lafuente, Miquel Tarradell, Alejandro Ramos Folqués y la propia Solveig Nordström (Nordström, 1967, p. 7)

En ésta época José Lafuente ostentaba un cargo como académico en la Real Academia de la Historia, habiendo sido previamente presidente de la Comisión Provincial de Monumentos de Alicante. Miquel Tarradell se hallaba en posesión de la Cátedra de Arqueología de la Universidad de Valencia desde 1956, era Comisario de Excavaciones Regional de Alicante y colaborador del Servicio de Investigación Prehistórica de Valencia, mientras que Alejandro Ramos Folqués, dueño de los terrenos del yacimiento de La Alcudia de Elche, era académico correspondiente de la Real Academia de la Historia (al igual que José Lafuente) y director del Museo Arqueológico Municipal de Elche. De este último destacan sus aportaciones a la clasificación de la cerámica ibérica y en la cronología de la escultura ibérica.

Cabe destacar como anécdota que Solveig Nordström comenzó la campaña de excavación en La Escuera de manera precipitada, es decir, antes de recibir el permiso de excavación legal. Ante esto Lafuente le espetó a Solveig:

- ¡Te van a poner en la cárcel!

- ¡No importa! Yo quiero comenzar. - respondió Solveig.

Esta inesperada respuesta demuestra el gran entusiasmo, predisposición y tesón por trabajar y conocer la arqueología del Mediterráneo. Realmente ella comenzó sus trabajos antes de recibir el permiso correspondiente, pero recalca que al poco tiempo recibieron los papeles y todo se desarrolló de manera legal.

Nos apunta como comenzó sus trabajos. Recuerda nada más llegar ver una gran plantación de algodón y alcachofas. Para comenzar la excavación, planteó ejecutar dos calicatas y gracias a su intuición las ubicó donde ella pensaba que podría obtener resultados óptimos para el estudio del yacimiento. Lo cierto es que, consciente o inconscientemente, las ubicó en ambos extremos del yacimiento.

4 Para saber más sobre el estudio de las monedas halladas en La Escuera consultar Llobregat, 1966, pp. 71-75; Villaronga, 1973; Ripollés, 1982; Ramón Sánchez, 2002. 
Solveig recuerda las palabras de Miquel Tarradell al respecto:

- ¡Qué calicatas más bonitas has hecho, es como si las hubiera hecho yo!

- Esas palabras resultaron clásicas en la primera campaña de La Escuera. De manera que tenían confianza en mí, porque Tarradell tenía que enseñarlo en la Universidad de Valencia.

Los resultados de estas primeras calicatas, como hemos comentado, fueron positivos, por lo que Nordström pudo volver a Estocolmo y presentar sus conclusiones al respecto. Con ello comenzó a conseguir los primeros aportes económicos para poder desarrollar la campaña de excavación, recibiendo de la Universidad de Estocolmo veinte mil pesetas y, a su vez, la Dirección General de Bellas Artes aportó la cantidad de seis mil pesetas (Nordström, 1967, p. 7).

Así pues, ante la importancia de los restos exhumados en dichas calicatas, Francisco Trías, dueño de la Finca de La Escuera, interrumpió las labores agrícolas y dio su beneplácito para acometer los trabajos arqueológicos, dando comienzo la que sería la primera campaña de excavación arqueológica en el yacimiento de La Escuera, el día 1 de junio de 1960 y que se prolongaría hasta noviembre del mismo año.

\subsection{Los trabajos de excavación.}

Tenemos constancia de que la excavación fue dirigida por Solveig Nordström a la cabeza de un equipo formado por Félix Rebollo Casanova, conservador y conserje del museo arqueológico provincial de Alicante en este momento, y un grupo de capataces, probablemente trabajadores de la propia finca,

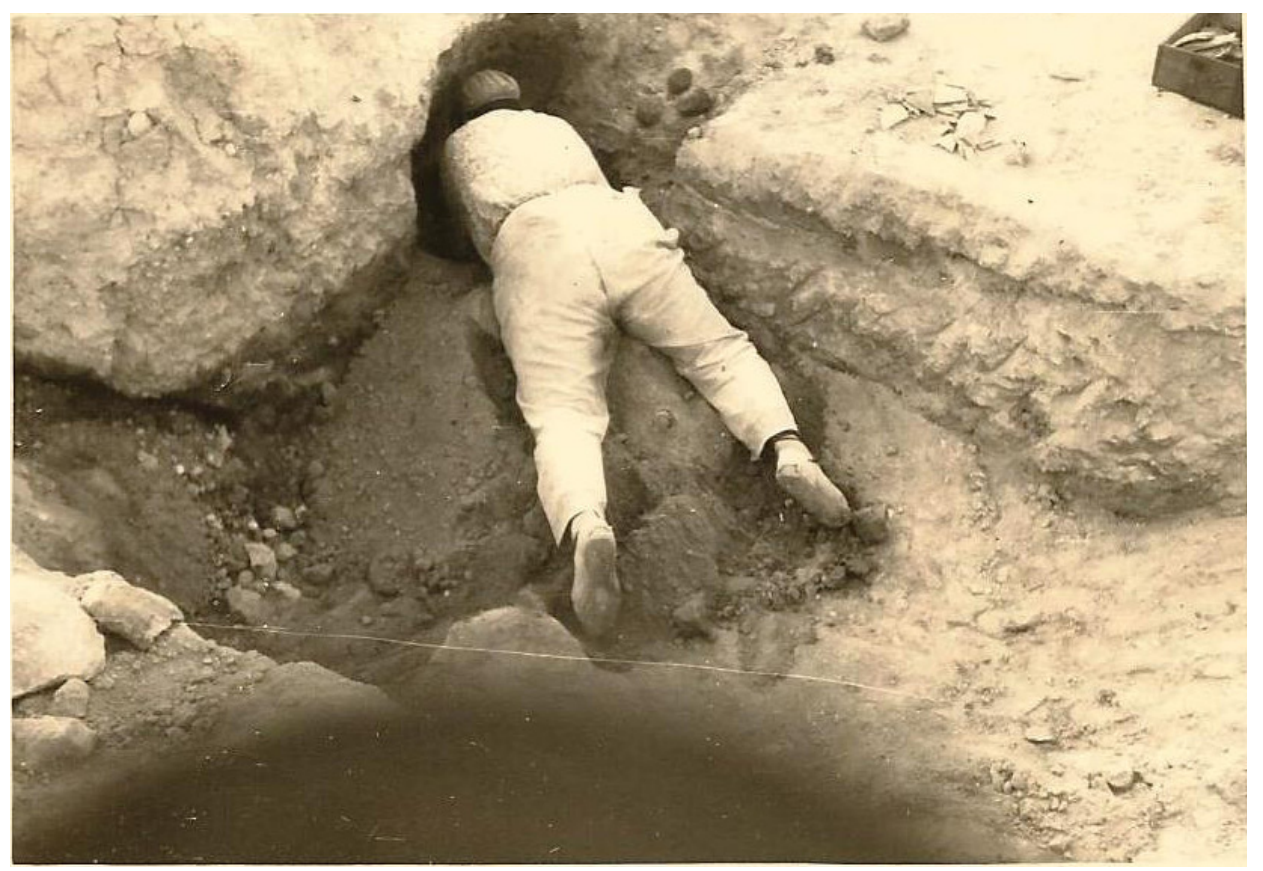

Fig. 1. Juan Berenguer, encargado de la finca, colaborando en los trabajos de excavación arqueológica. Archivo Juan José Berenguer.

que colaboraban en las labores de excavación (Fig. 1).

Félix Rebollo (Fig. 2) es recordado por Solveig de la siguiente manera:

- Siempre iba bien uniformado, con botones de oro, al parecer eran falsos (bromea) pero eran muy 


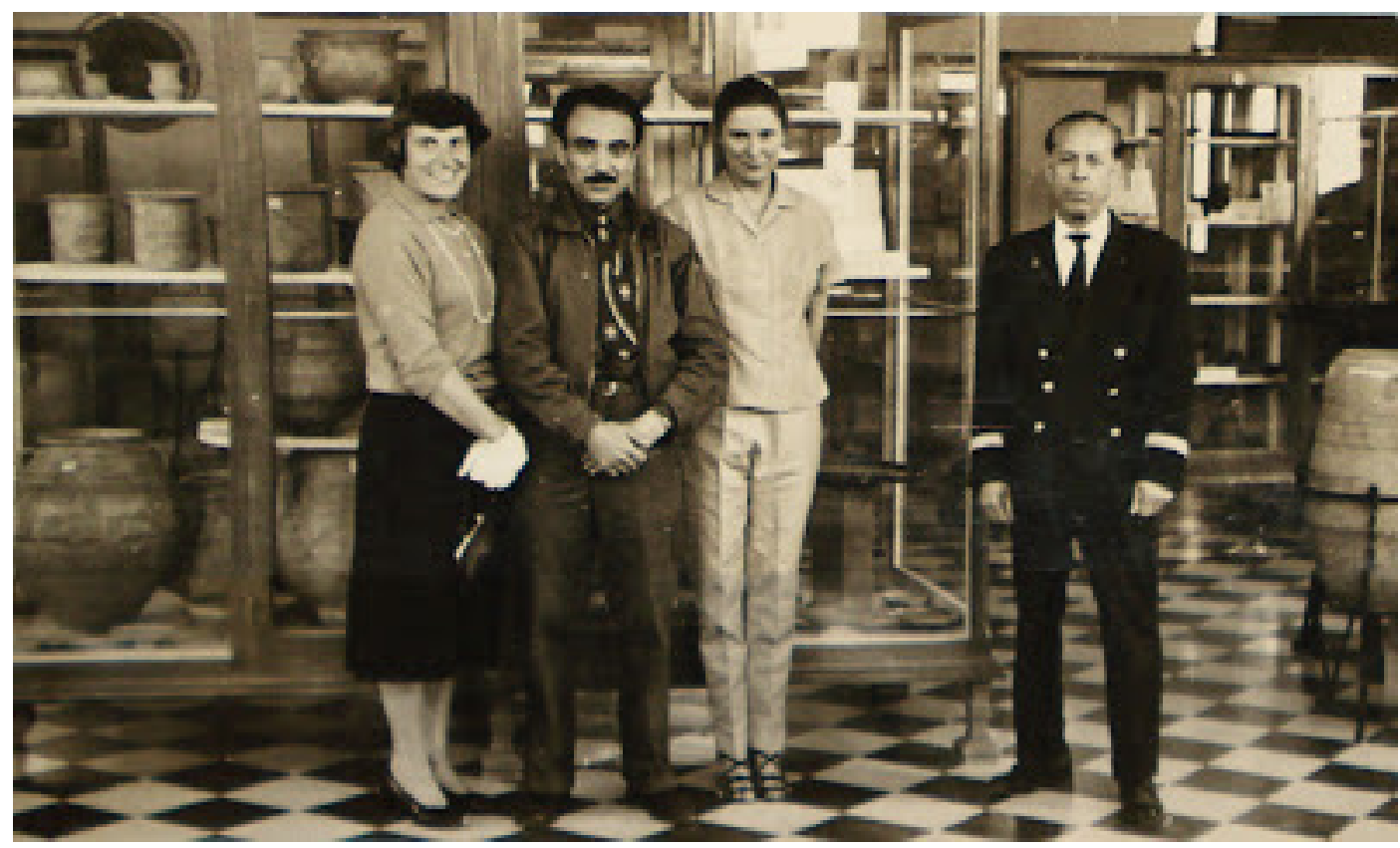

Fig. 2. Solveig Nordström (segunda por la derecha) junto a Félix Rebollo (derecha) en el museo arqueológico provincial de Alicante. http://www.lucentumysuhistoriaenpapel.com/search/label/ PERSONAJE\%3A\%20SOLVEIG\%20NORDSTROM

muy brillantes, sí; siempre muy digno, así, pero la verdad es que él me ayudaba mucho, sí. Él también venía cada domingo a San Fulgencio e íbamos a la playa de La Marina, donde con la ayuda de la arena aprovechábamos para reconstruir las piezas que encontrábamos en la excavación, él me enseñó cómo hacerlo".

Posteriormente nos relató un acontecimiento que ella recuerda con especial cariño: la colaboración de sus alumnos suecos (Fig. 3). Ese mismo verano acudieron un grupo de seis alumnos procedentes del Instituto de Varnamo. Ella dice que admira a sus alumnos, y no es para menos.

Como ya henos comentado anteriormente, la perspectiva que se tenía de España en países como Suecia, era de un país inseguro, donde imperaba una fuerte dictadura, encerrada en sus propias fronteras y sumida en un estado de pobreza tras la post-guerra. Cabe destacar que a Solveig no le permitieron presentar su tesis en castellano por ser considerado un idioma incivilizado y nadie le apoyó en su idea de estudiar la arqueología española. Suponemos que esta perspectiva comenzó a dar sus primeros pasos hacia el cambio tras la presentación asidua que Solveig iba haciendo de sus trabajos en España a través la Universidad de Estocolmo.

- Los suecos tenían un poco de miedo a España. Me ofendieron cuando yo había escrito mi tesis doctoral y yo la había escrito en español y quise publicarlo en la Universidad de Estocolmo.

- ¡Ah! Un tema de España. Si por lo menos lo hubieras escrito en un idioma civilizado - me dijeron.

- Eso me dolía mucho, sí, porque el español es más civilizado que el sueco ¿verdad? (sonríe). El español es casi latín, sí. Es casi latín. El latín no queda tan puro en ningún otro idioma como en español, sí. Pero bien, yo tuve que traducirla al francés, por eso que mi tesis está en francés ahora, yo lo había escrito en castellano.

Seguramente en alguna de sus ponencias en Suecia picó la curiosidad a este grupo de seis alumnos que sin duda decidieron echar una mano a su compatriota sueca en España, atraídos por los relevantes estudios de su maestra. De tal modo que, ni cortos ni perezosos, se dispusieron a realizar el trayecto 


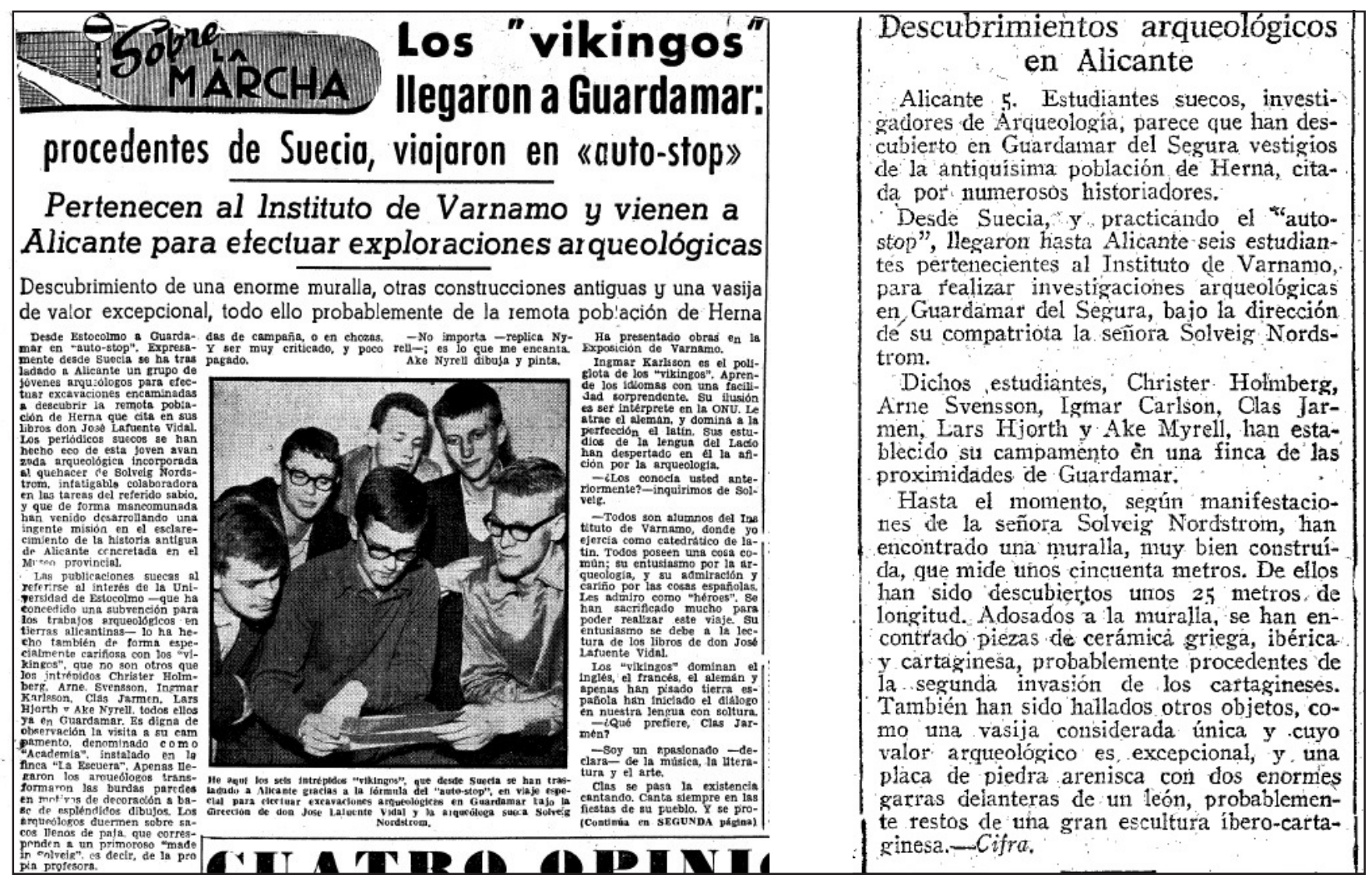

Fig. 3. Recortes de prensa. A la izquierda diario Información de Alicante, domingo 3 de julio de 1960, pp. 9-10. A la derecha periódico ABC edición de Madrid del miércoles día 6 de julio de 1960, p. 48.

Estocolmo - Alicante ni más ni menos que en "auto-stop". La prensa tanto local como nacional se hizo eco de este hecho tan excepcional.

La visita de estos alumnos Solveig la recuerda con gran admiración e ilusión:

- Yo admiro a mis alumnos, está claro, eran suecos, tenían costumbre de vivir una vida cómoda y tenían que vivir allí en el campo y claro, yo no tenía dinero para buscarles un hotel, sino que yo encontré allí un viejo almacén para que ellos pudieran dormir. Pero claro ¡no podían dormir en el suelo! Fui a comprar telas con las que coser colchones, pero claro ¡ hasta eso era caro! Y el vendedor me las regaló y no tuvimos que pagar. Así yo cosí colchones y los llené de paja. Al poco tiempo los alumnos se pusieron enfermos y comencé a tener miedo. Especialmente uno tenía todo el cuerpo rojo y mucho picor.

Acudimos a uno de los hijos de don José Lafuente, que era médico y nos dijo:

- ¡Ahá! Es fácil, es un bicho, tenéis bichos en los colchones - Dijo. Que no es una enfermedad, son bichos ¡No podéis vivir así!

- Tuvieron que sufrir mucho ¿sabes? Luego tuvieron que volver a Suecia a terminar sus estudios, pero admitieron que gracias a este viaje que pudieron realizar a España, Sol nos ha enseñado mucho para el resto de nuestra vida. No hemos podido seguir con la arqueología, pero todo lo que hemos hecho nos ha servido. 
Reconoce Solveig que se trataba de una excavación escasa de recursos logísticos:

- El problema es que no teníamos una carretilla para quitar los escombros. Las carretillas eran caras, pero pronto se resolvió el problema, porque vinieron mis seis alumnos suecos, sí, a ayudarme a excavar. Ellos y yo hemos bailado y cantado en los bares y ya hemos ganado un poco de dinero y ya hemos podido comprar la carretilla - relata mientras nos reímos. Pero luego la Universidad de Valencia nos dio un poco, y más nos dio el Rey Gustavo Adolfo VI de Suecia.

La relación con todo el personal que rodeaba la excavación: capataces, trabajadores de la finca, visitantes e incluso propietarios de la misma, Solveig lo recuerda todo con gran cariño y ternura. Al ser preguntada sobre cómo la gente le trató allí ella respondió.

- ¡Me sentía muy feliz! ¡Ay! ¡Cómo hermanos! Muy felices. Y de vez en cuando Félix tocaba la guitarra ${ }^{5}$ y cantaba, sí y los dos chicos de Guardamar me traían cacahuetes, como no tenía gran cosa para comer en La Escuera me traían cacahuetes. Y también me traían melones, comía mucho melón y cacahuetes. A veces venían los dueños de la finca también con su hijo pequeño, eran muy simpáticos. Éramos como una gran familia.

A continuación ella recordaba con asombro uno de los descubrimientos más relevantes en La Escuera, la píxide de borde dentado.

- Los obreros tenían que quitar los escombros pero luego en seguida yo me arrodillé y comencé a excavar con las manos o con un cepillo fino. Me acuerdo especialmente, la vasija que llamábamos "el huevo de avestruz", una de las vasijas más famosas de España, sí. Yo estaba arrodillada, encontré un tiesto y veía allí uno de los picos, porque la vasija estaba como muy inteligentemente cortada ¿verdad? Y lo primero que yo encontré era una fila de picos.

- ¡Ay! - dije yo. A ver si encontramos una vasija de huevo de avestruz. Ya luego encontré todo y yo estaba de rodillas así, y se acercaron los obreros a ver:

- ¡Ah! ¡Ah! ¡Qué bonito! ¡Qué bonito!

- Pero todo eso excavaba yo con mis uñas fuertes. Era tan delicado, tan delicado. Y casi toda la vasija junta. Faltaba muy poco, pero no encontramos la tapadera, a ver si la encontráis vosotros porque tiene que existir. Sí, sí, sí. Y bien, pero claro, era fenomenal, esa vasija estaba completamente limpia, no había restos ni de grasa, ni de cereales, ni nada dentro, completamente limpia. Y yo estaba tan feliz... pero así con muchas otras vasijas. Lo bonito es que muchas veces se encontraba bastante juntos los tiestos, sí.

- Luego quizás debería añadir que esa vasija del huevo de avestruz... yo pensé en seguida: esta es una gran vasija de un templo que han usado en un ritual. Esto pensaba yo al descubrir esta vasija antes de saber que era un templo. Luego me sacaron fotos los periodistas con esa vasija en mis brazos y yo salí en el diario Información como la sacerdotisa del huevo de avestruz (Fig. 4).

- Tenía que ser una vasija que han usado en las ceremonias porque no han quemado nada en la vasija, está limpia, limpia, más bien para llevar cosas secas, cereales o frutas o algo, quizás en las procesiones, como las damas iban con vasijas en la cabeza en las procesiones, vasijas con cereales y frutas, algo así pensaba yo. Como hemos visto en Atenas, por ejemplo en la Acrópolis, así las Korai, iban con cestos así, pero claro era más bien vasija en forma de kalathos pero claro es tan grande que también

5 Según otra fuente consultada, Juan José Berenguer, quien estuvo presente durante las excavaciones cuando era niño, apunta que Félix acudía siempre con un acordeón al yacimiento para amenizar las tardes. 


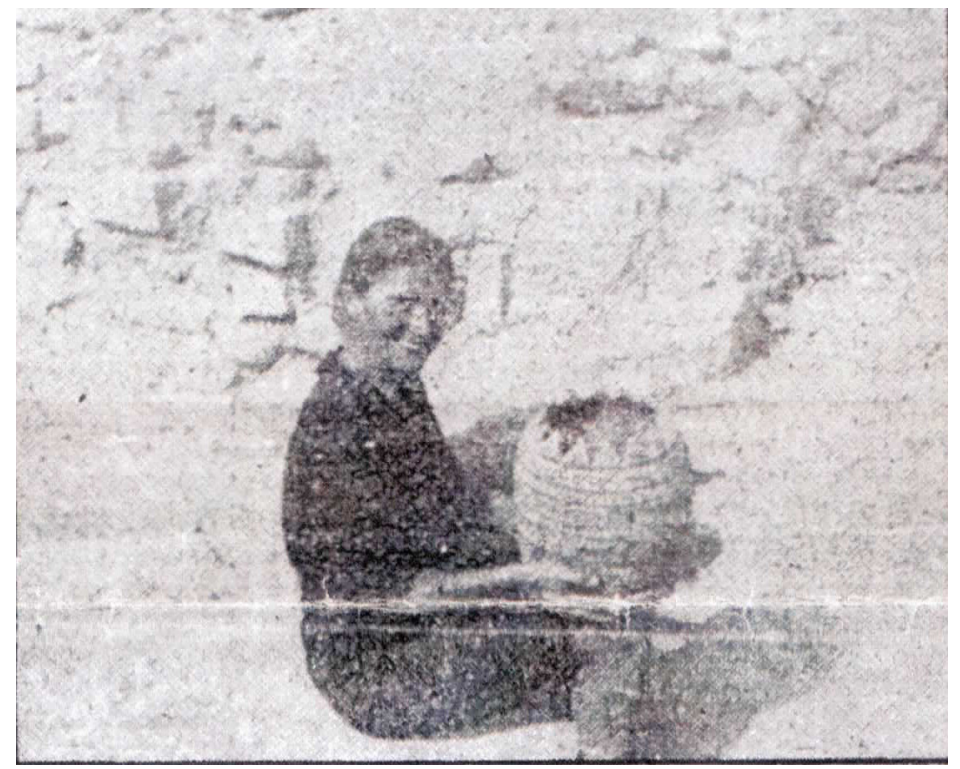

Fig. 4. Imagen de Solveig Nordström en La Escuera con el vaso dentado.

hubiera podido servir para transportar una cosa que no sería líquida porque había dos filas de agujeros: vino no, vino no por ejemplo -comenta mientras emana una carcajada-. Además el vino hubiera dejado marcas... ni agua. Pero habían agujeros, dos filas de agujeros, y yo interpretaba en los dibujos como flores de loto estilizados.

También recordó otros tantos hallazgos relevantes en su campaña en La Escuera como el vaso geminado, del cual recuerda que eran para hacer libaciones, las ya mencionadas monedas, las basas de columnas o la jarrita de asa trenzada, de la cual apunta:

- También es muy importante y también figura en mi tesis ¿verdad? Sí, sí. También hubiera podido ser una vasija ceremonial, sí, con sus dibujos de hojas de hiedra que son sagradas también. También encontramos las garras de un león en piedra, sí y unos... ¿cómo digo?. Como tambores muy grandes, muy grandes, que tienen que ser restos de columnas. Una mañana, cuando yo llegué a las excavaciones, había dos hombres allí, tocando uno de los tambores de columnas y yo dije:

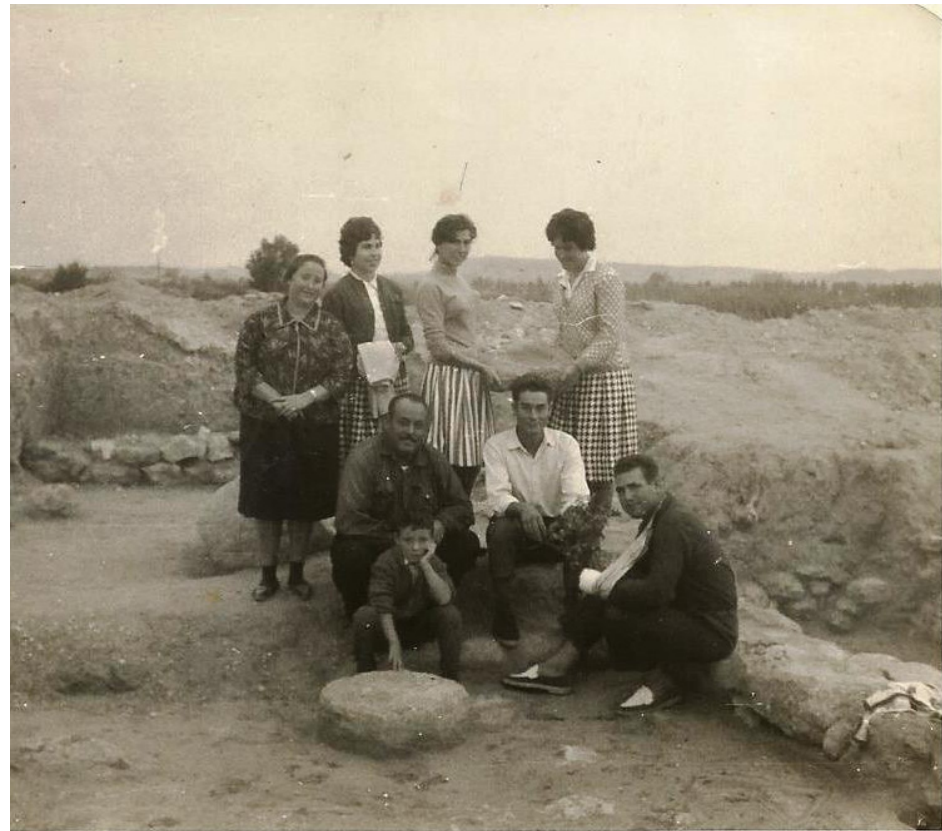

Fig. 5. Imagen donde aparece Juan Berenguer, encargado de la finca, con Catalina Conejero, su esposa (izquierda), ysu hijoJuan JoséBerenguer, acompañados de un grupo de visitantes posando en el templo situado en el Bancal B. Archivo Juan José Berenguer.
- Pero ¿Qué queréis hacer?

- Queremos ver el tesoro que está por abajo, dijeron.

- Eso -dije- No (negando firmemente con el dedo y entre risas). Mientras que yo viva no vamos a buscar tesoros por debajo de mis columnas.

- Y claro, venía mucha gente a vernos. Los excursionistas de Elche vinieron de vez en cuando. Ellos se portaron muy bien. Me invitaron a la Basílica de Elche el 15 de agosto a ver el Misterio, y luego yo iba cada 15 de agosto a Elche, me encantaba. Aún iría, sí. Bien, y tuve muchas amistades, y claro, más que todo la gente de la finca que siempre pasaron a visitarme y a ayudarme (Fig. 5).

Al ser cuestionada por cómo se plantea y como se desarrolla la campaña de excavación ella responde lo siguiente:

- Bien, bueno, yo siempre intentando tener mucho cuidado de no estropear nada, y siempre apuntar bien donde salió cada detalle e intentando seguir la estratigrafía ¿verdad? Y no revolcar todo así, sino intentando ser muy científico como yo había 
aprendido en Estocolmo. Yo en Estocolmo había estudiado con el gran profesor Gösta Säflund, sí. Él me había enseñado, ¿verdad? que es muy importante la estratigrafía, y hay que hacer calicatas, fue él quien me enseñó a hacer las calicatas, estas que luego le gustaron tanto al profesor Tarradell (entre risas) y claro siempre apuntando cada detalle. Pero claro, yo tenía cuadernos y bolis, todo era muy primitivo, claro, yo no tenía aparatos modernos, y claro, ordenadores y eso, yo nunca había visto un ordenador, sino todo a base de papeles y bolis, apuntando cada cosa: las medidas, la situación de cada cosa...

Sobre el gran edificio del Bancal B ella siempre defendió sus funciones cultuales como templo, y nos reveló qué descubrió en ese espacio para conducirle a esa interpretación.

- Había como un altar de barro, muy liso pero muy grande y como yo había estudiado mucho en Olimpia, en Grecia, allí tenían altares de barro alrededor del gran templo de Zeus en Olimpia y por eso yo lo vi en seguida: es un altar, es como si estuviéramos en Olimpia, sí. Y me hubiera gustado poder hacer también un examen químico a ver lo que había porque había una clase de grasa, claro, yo pensé que allí habían sacrificado animales y aceites, pero claro, no estaba en mi poder hacer un análisis químico de esa grasa que estaba en el altar, pero esto hubiera sido muy interesante, sí.

Su modo de excavar tampoco nos deja indiferentes. En los trabajos que requerían mover cantidades de tierra considerable era ayudada por el personal de la finca por medio de picos y legones; para situaciones que requerían de mayor precisión ella utilizaba sus propias manos:

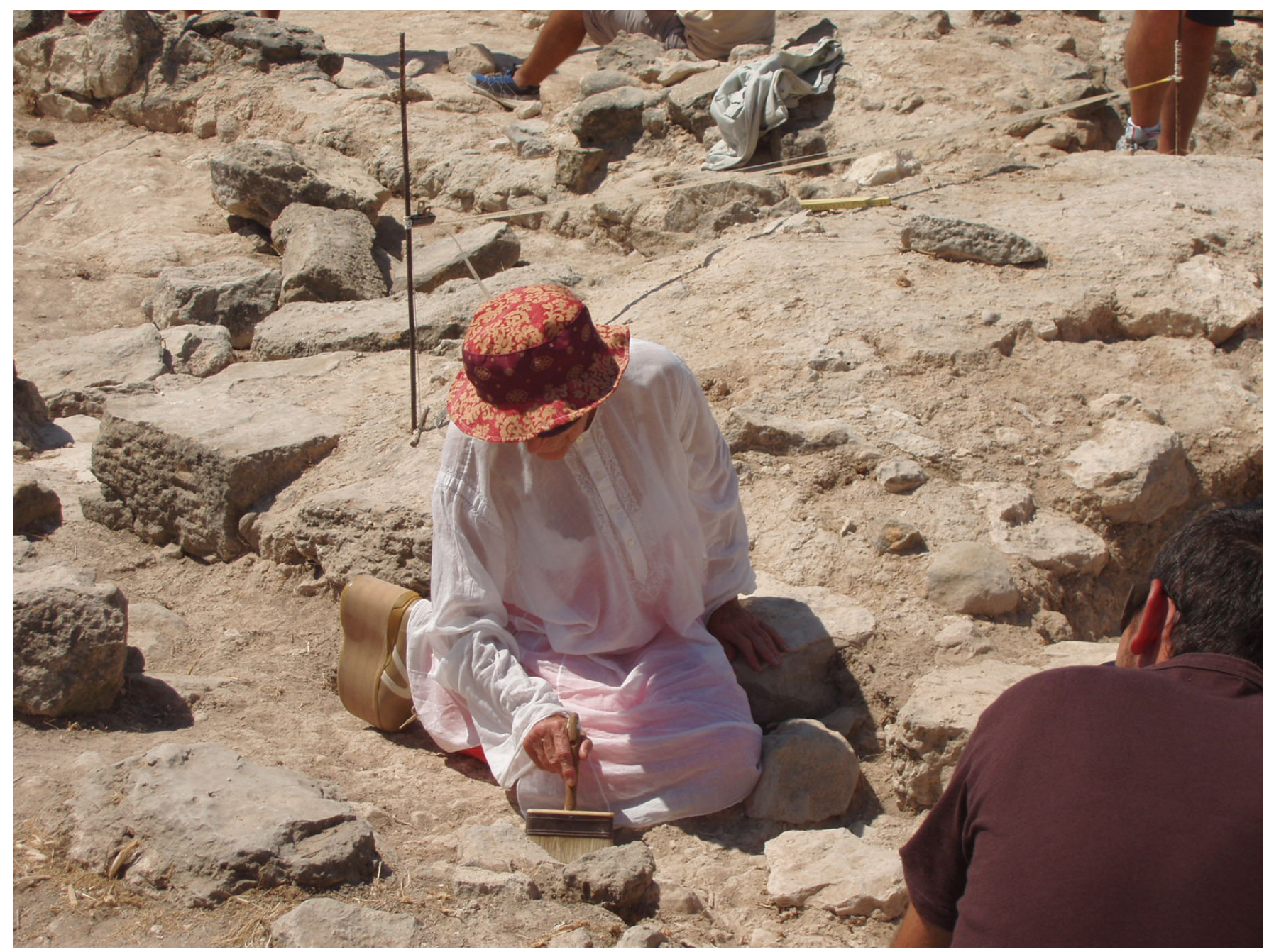

Fig. 6. Imagen de Solveig Nordström excavando en su visita a La Escuera en la campaña de 2007. 
- Cuando llegamos a cosas más delicadas, yo siempre excavaba con las manos, jaún tengo las uñas estropeadas! - nos relata gesticulando y entre risas. Hasta cuando estuvimos en La Escuera de visita hace un par de años, ¿verdad?, me colocaron allí y yo comencé a excavar con las manos. Vinieron con un cepillo porque no lo veían muy elegante que una arqueóloga tan famosa excavara con las uñas, pero como yo tenía costumbre de excavar con las manos... No me fiaba ni del cepillo, y es que las manos son muy sensitivas - apunta nuestra arqueóloga (Fig. 6).

Gracias a Sol (así se dirigen a ella sus más allegados) La Escuera ha traspasado fronteras. Ella visitaba cada cierto tiempo Suecia, donde aprovechaba para realizar pequeñas charlas sobre sus trabajos en España.

- En cierta ocasión recuerdo que el profesor Gösta Säflund había invitado a mucha gente a la Universidad y yo iba a hablar en esa ocasión sobre La Escuera. Comencé diciendo: Bienvenidos a "la finca". La gente se extenuó. Es que finca en sueco es una palabra muy fea, significa cárcel - nos explica sonriendo - pero yo busqué esa palabra exactamente para golpearles un poco, para darles como un pequeño choque, pero quedaron muy impresionados con mis pequeñas charlas y las fotos que yo les mostraba.

La campaña de excavación finalizó en noviembre de 1960. Seis meses de intenso trabajo que daría como resultado, siete años después, una excelente publicación científica, describiendo al detalle cada actuación, complementada con precisas descripciones y acompañada de los correspondientes planos, secciones y fotografías, lo que demuestra una gran labor científica para la época.

Recuerda con nostalgia cómo cerraron la campaña de excavación en La Escuera, básicamente por falta de recursos y de los correspondientes permisos:

- Me dolió cuando tenía que abandonarla pero claro... yo tampoco tenía derecho a colocarme allí excavando, ya me hubieran colocado en la cárcel, así no se hace.

Siempre estuvo muy agradecida al rey de Suecia Gustavo VI Adolfo, el cual le otorgó la beca "Kungafonden", por medio de la cual pudo ampliar su estancia en España para realizar el estudio pormenorizado de los materiales (Nordström, 1967, p.7).

Solveig siempre intentó mostrar a España como un país rico en cultura, un país por conocer y por explotar científica y arqueológicamente hablando, demostrar a Suecia como España era un país interesante y por explotar en el campo de la arqueología. Su intención siempre fue crear un estrecho vínculo entre España y Suecia:

- Yo siempre he querido comenzar una colaboración íntima entre Suecia y España científicamente, económicamente y humanamente. Iba corriendo por las calles vendiendo latas de alcachofas de España, corriendo por las calles de Estocolmo: -¿Habéis visto qué alcachofas más bonitas?, Suecia nunca había visto una alcachofa por entonces, y zapatos, también quería vender zapatos ${ }^{6}$. Iba luchando pero... los suecos tenían un poco de miedo a España.

Comenta que en Suecia siempre han tenido fijación por Italia. De hecho Roma cuenta con el Instituto Svedese, fundado en 1925 por el propio Gustavo Adolfo VI, en aquella época príncipe heredero. Ella estuvo allí estudiando y realizando parte de su tesis doctoral como hemos comentado anteriormente. Recuerda como en una ocasión recibió la visita del rey sueco.

6 Aludimos este hecho a su estancia en Elda y la entrevista efectuada a Nordström por Susana Esteve, publicada en el semanario Valle de Elda publicado el 31 de octubre de 2014, pp. 8-9, con motivo de su visita para conceder una conferencia sobre "el Maestro del Monastil". 
- Él se interesó por los libros que yo tenía allí. De mi tesis yo primero publiqué el primer volumen y el segundo lo publiqué con ayuda del rey. Tengo una carta de él cuando dice:

- Ya le voy a dar un poco de dinero para publicar el segundo volumen de su tesis.

- Si él hubiera seguido viviendo un poco más hubiéramos podido hacer más cosas (comenta frotándose las manos). Yo solicité tener también un instituto sueco en España, pero nunca lo hicieron.

Después de todo, la vida de Solveig no ha sido nada fácil. Ganarse la vida en aquella época como arqueólogo era una ardua tarea. Se vio forzada a abandonar la arqueología por falta de recursos.

- Vivía en maletas ¿sabes? Hubiera querido hacer más. Un día quedé desmayada en una plazoleta en Benidorm porque tenía tanta hambre... sí, al lado de la iglesia, pero pasó el cura, menos mal. Yo lo conocía, era un arqueólogo laico, don Luis, pero muy simpático, y él me cogió en sus brazos, me llevó a casa y me dio de comer y dijo:

- Yo voy contigo al colegio Lope de Vega y te presentaré como profesora de latín y griego.

- Sí. El vino conmigo y me presentó, y contestaron:

- Desgraciadamente no necesitamos ningún profesor de griego y latín, lo que necesitamos es una profesora de ballet clásico.

- Aquí me tienes - dije yo. Yo soy también profesora de ballet clásico.

- Y así vivía un poco. Siempre he sido pobre, no tengo nada en este mundo, ni un centímetro de tierra, pero tengo un gran parque en Alicante- bromea entre risas.

- Cuando me hicieron el homenaje en el Tossal de Manises propuse que cuando yo muera yo prefiero echar mis cenizas allí, pero también hay otra posibilidad: que lo pongan en La Escuera en algún sitio. Sería bonito. A lo mejor mis cenizas pueden traer suerte a las ruinas. Yo creo en estas cosas. Y dijeron:

- Vamos a hacerte una escultura, una estatua.

- ¿Para qué?, mejor dar ese dinero a los que tengan hambre, pero si yo puedo mandar algo que pongan mis cenizas en Lucentum o en La Escuera pero sin una cúpula, entre las piedras de allí.

Tras dialogar con la Dra. Solveig Nordström y recordar tan gratos recuerdos sobre su actividad en La Escuera a través del relato de sus vivencias, sus sentimientos, sus trabajos e incluso de las fotografías que ilustran esos primeros años en Alicante nos confesó:

- Os felicito, me hace tan feliz... porque yo casi había dejado de pensar en La Escuera, eso era una cosa de juventud, porque muchas cosas comenzamos y no pudimos terminar, así es la vida.

\section{CONCLUSIONES.}

Hemos podido conocer de primera mano gracias a la amabilidad de Solveig Nordström como era una excavación arqueológica en la década de los años 60 en España. No cabe duda que el éxito de su excavación venía promovida por la gran pasión que Solveig ponía en su trabajo. Dedicación, amor, constancia y esfuerzo es lo que ha caracterizado a nuestra entrevistada durante su intervención. 
Su método de trabajo para la época y más para un país como España en esos tiempos son ejemplares. Sus croquis, planos, secciones y fotografías son dignos de admirar a sabiendas de los pocos recursos con los que contaba, y la publicación de los resultados es simplemente un modelo de referencia que incluso hoy en día nos es de gran utilidad para trabajar sobre el yacimiento, así como para investigar ciertos aspectos de La Escuera. Su preocupación por llevar a cabo un registro exhaustivo tanto de la estratigrafía como de los hallazgos llama especialmente la atención, aptitudes estas adquiridas por su preparación académica de la mano de Gösta Säflund. Esto se vio reflejado en la confianza que los miembros de la comisión de excavación depositaron en la joven Solveig para dirigir la campaña.

Que Solveig Nordström haya efectuado los trabajos de excavación arqueológica en La Escuera fue un hecho muy importante para la arqueología ibérica en general y la arqueología alicantina en particular. Gracias a esta excavación y posterior publicación podemos conocer hoy uno de los yacimientos más importantes en el ámbito de la Contestania ibérica y le debemos a ella la difusión de sus resultados, de tal modo que con el paso del tiempo se ha podido seguir estudiando y avanzando en el conocimiento del mundo ibérico.

Sin duda ha sido un auténtico privilegio y honor poder hacer esta entrevista a esta gran arqueóloga. Alicante ha tenido el inmenso privilegio de disponer de tal prominente investigadora que tanto nos ha dado a conocer de nuestra propia historia. Con su incesante y excelente trabajo nos ha revelado un poco más de nuestro pasado. Una persona que emana amor, paz y pasión por todo lo que hace, vive, cuenta... proveniente de tan lejos pero sin embargo tan cercana a todo el mundo. Tan grande pero tan humilde a la vez. Solo nos queda agradecer a Sol todo lo que ella nos ha dado. Gracias.

\section{BIBLIOGRAFÍA.}

Berenguer González, R. (2013). Análisis microespacial del templo ibérico de La Escuera (San Fulgencio, Alicante), Los Lugares de la Historia, Col. Temas y Perspectivas de la Historia, vol.3, Salamanca, pp. 885-907.

Jully, J. J., Nordström, S. (1972). Une forme de céramique ibéro-languedocinne: La jarre bitronconique, APL XIII, pp. 93-101. Valencia.

Le Golf, C.J. (2011). Solveig el pajarito que sobrevoló el Tossal de Manises. Alicante. http://www. lucentumysuhistoriaenpapel.com/2011/12/ solveig-nordstrom-el-pajarito-que-salvo.html (consultado el: 30-05-2016).

Nordström, S. (1961). Los cartagineses en la costa alicantina. Alicante.

Nordström, S. (1967). Excavaciones en el poblado ibérico de La Escuera (San Fulgencio, Alicante). T.V. del SIP. Valencia.

Nordström, S. (1968). Los ojos en los oenochoes ibéricos en el Levante español. Studies in Classical Archaeology, V, Opuscula K. Kerenyi dedicata.
Nordström, S. (1968). Representaciones de aves en la cerámica ibérica del sureste de España. Opuscula Romana. 6, pp. 97-120.

Nordström, S. (1969 - 1973). La ceramique peinte ibèrique de la province d'Alicante. Estocolmo. (Vol. I-II).

Molina, J., Molina, M.C., Nordström, S. (1976). Coimbra del Barranco Ancho (Jumilla, Murcia). T.V. del SIP. Valencia.

Roca de Togores Muñoz, C. (2006). Joaquín de Rojas. Primer director del museo arqueológico provincial de Alicante. MARQ, Arqueología y Museos, 01. Alicante.

Rosser Limiñana, P. (2015). Historias y arqueólogos en Alicante, Historiografía arqueológica de los siglos XIX y XX. Alicante.

Sala Sellés, F. (2010). Nuevas perspectivas sobre las relaciones púnicas con la costa ibérica del sureste peninsular. Mainake , no 32, pp. 933950. 